\title{
Mapping Out a Strategy: Curriculum Mapping Applied to Outreach and Instruction Programs
}

\section{Sarah LeMire and Stephanie J. Graves}

Academic libraries use two common methods to reach first-year students: outreach activities and library instruction. The purpose of this study was to discover if curriculum mapping techniques commonly used in library instruction could be applied to outreach to explore the synergies and differences between programs. The project demonstrated that mapping was an effective tool for gaining insight into interrelated outcomes, resource allocation, consistency of library messaging, and students reached by each program. Curriculum mapping proved a useful method for creating strategic and intentional instruction and outreach programs that complement rather than compete with each other.

\section{Introduction}

Libraries increasingly engage in outreach activities to better familiarize students with resources and services. Programs commonly focus on incoming first-year students who are unfamiliar with the campus library. Outreach activities can vary as much as the campuses that they serve, ranging from more traditional resource fairs, open houses, and orientation presentations to less traditional events such as zombies vs. humans games in the library, library luaus, and Amazing Race-inspired games. Despite their differences in approach, library first-year outreach activities often share a common goal: to familiarize incoming students with the library and reduce the level of library anxiety these students may be experiencing in their introduction to college. However, libraries often conduct outreach activities on an ad hoc basis, with different librarians staffing and coordinating them. Surprisingly, these outreach activities are rarely aligned with information literacy instruction programs, although they share similar goals. Indeed, library outreach programming often lacks the intentionality and planning that has become a staple of good instruction programs. This lack of intentionality can cause confusion if students attend multiple orientation events and instruction sessions, receiving redundant or even conflicting messaging about the library. Without the benefit of a programmatic approach to connect outreach events to instruction, it can be difficult to provide students with clear, consistent, and scaffolded messaging about the library. However, if libraries view outreach as a curricular activity, they can easily map it onto existing instruction efforts.

\footnotetext{
* Sarah LeMire is First Year Programs Coordinator and Stephanie J. Graves is Director of Learning and Outreach, both at Texas AEM University Libraries; email: slemire@library.tamu.edu, stephaniegraves@tamu.edu. (C2019 Sarah LeMire and Stephanie J. Graves, Attribution-NonCommercial (http://creativecommons.org/licenses/bync/4.0/) CC BY-NC.
} 
Curriculum mapping is a technique that visually represents curricular data, such as learning outcomes, level of instruction, and library instruction statistics, to improve program analysis. Libraries commonly use it as a method for illustrating connections between library instruction and the university curriculum, determining overlaps in library instruction, and identifying opportunities for increasing instruction. Mapping also aids in uncovering courses, and therefore student populations, that are underserved by the instruction program. By highlighting these connections and deficiencies, libraries can use curriculum mapping as an assessment tool to better align library learning outcomes and course learning outcomes. Mapping can facilitate greater intentionality and strategic allocation of resources in library instruction programs and help create a scaffolded information literacy curriculum that supports greater depth in information literacy learning. Since curriculum mapping is a strategy that can improve instruction programs, can it be applied to outreach activities to accomplish similar outcomes?

The researchers, both instruction and outreach librarians at Texas A\&M University, struggled with similarities and tensions between outreach and instruction programming for first-year students. Where should resources, time, and energy be expended to maximize the library's message to first-year students? The researchers embarked on a project to discover if curriculum mapping techniques could be applied to outreach activities to better understand the interrelated nature of outreach and instruction programming. The project goals and research questions included the following:

- Question 1: Can curriculum mapping be applied to library outreach and instructional programs to create synergies, intentionality, and scaffolded outcomes that serve both programs?

- Question 2: Can curriculum mapping illuminate student populations that are receiving library messaging in both outreach and instruction and those that are not?

- Question 3: Can curriculum mapping of the outreach and instruction programs together be used to identify redundancy in messaging and clarify the strategic allocation of library resources?

To investigate these questions, the researchers focused on a curriculum mapping project examining first-year instruction and outreach at the Texas A\&M University Libraries.

\section{Institutional Background}

The University Libraries consists of five libraries located in different parts of a sprawling campus in College Station, Texas, and boasts a robust instruction and outreach program. In this institutional context, outreach is considered to be any event or programming that predominantly describes library resources and/or promotes awareness of library services. In contrast, the Libraries defines instruction as the process of teaching learners conceptual knowledge or practical skills related to information literacy. A major element of the Libraries' instruction and outreach programs is focused on first-year students. With an enrollment of more than 60,000 students, the first-year student population exceeds 12,000, including both first-time college students and students transferring from other institutions. Library employees staff more than 60 outreach events in the summer months leading into the fall semester to ensure that incoming students receive a friendly welcome to campus and are aware of the library resources and services available to them. Additional activities precede the spring semester. Outreach activities include orientation presentations, resource tables at new student resource fairs, participation 
in first-year orientation camps, and a large library open house event that draws more than 4,000 students in one afternoon. Once the academic year begins, first-year instruction occurs in composition courses, learning communities, and introductory disciplinary courses. Though librarians teach nearly 200 instruction sessions per year in lower-division classes, the average class size for those sessions is relatively small at approximately 25 students. Due to the scale of the Libraries' outreach program and the size of some of the campus outreach events, the number of students that librarians interact with at outreach events exceeds the number of students seen during instruction sessions by approximately a factor of four. To accommodate the scale of both the outreach and instruction programming, a community of librarians and library staff must work collaboratively to fulfill commitments. Clear goals, outcomes, and consistent messaging are vital to creating a programmatic outreach and instruction program.

\section{Literature Review}

An increasing number of studies employing curriculum mapping have been reported in the library literature. ${ }^{1}$ Curriculum mapping has been established as an important strategy that academic libraries are using to identify instruction opportunities within the academic curriculum $^{2}$ and improve communication with disciplinary faculty and administration. ${ }^{3}$ These systematic approaches also aid libraries in their abilities to strategically allocate resources and demonstrate the value of library instruction. At the same time that libraries are creating more systematic approaches to library instruction, the literature also reveals that libraries are engaging in more robust outreach efforts to reach their students, staff, and faculty. ${ }^{4}$ Library instruction and library outreach share commonalities. Both activities serve as a touchpoint for librarians to educate users about the value of the library services and the impact of those resources on user success. However, librarians have yet to explore the potential for curriculum mapping to improve the programmatic impact of outreach programs and establish connections between outreach and instruction efforts.

Instruction programs and the library outreach movement rarely intersect in the library literature. The outreach literature lacks the program maturity often seen in library instruction programs. Articles speak about creative library outreach events, but there is a gap in the literature regarding more systematic approaches to multiple outreach events, how those events inform and build upon each other, and how the total body of library outreach events provides value to the library's mission. Many libraries lack a defined outreach program or department, and there is little research on the formation of outreach programs with specific outreach goals, outcomes, budgets, and staffing. Further complicating the issue, the profession lacks a shared understanding for the term "outreach." Some libraries define outreach as programs targeting community-based or general public populations, while others define outreach as promoting library services to the academic community. ${ }^{5}$ Moreover, outreach programming can be tightly linked to marketing and public relations strategies, sometimes sharing the analogous goal of improving awareness of library services ${ }^{6}$ How a library defines outreach may determine if and how outreach is seen as a separate activity or if it is integrated into library instruction programming. Furthermore, if outreach is defined as marketing strategies for singular events or services, it can lack a holistic strategy that takes into account other activities such as instruction.

There are a few examples of libraries beginning to institutionalize outreach programs in a small and local context. Fabian et al. demonstrated a strategic approach by using program- 
ming commonly found in public libraries and corporate business models to plan and assess outreach events over the course of one year. ${ }^{7}$ Hallmark, Schwartz, and Roy advocated for the creation of a library outreach and marketing campaign to demonstrate the value of the academic library as the center of campus life. ${ }^{8}$ The same authors later published the University of Texas at Austin Fine Arts Library marketing and outreach plan, with initiatives designed to reach undergraduates through faculty members. ${ }^{9}$

Librarians struggling with strategic implementation of outreach programs have conducted surveys to gain a better understanding of professional norms. Dennis surveyed fellow outreach librarians to find 21 unique and successful outreach events delivered between 2009 and 2011, each implemented by librarians with different formal responsibilities for outreach at their respective institutions. ${ }^{10}$ Resource allocation for systematic outreach programs is also a concern among librarians. Carter and Seaman's survey of university libraries uncovered major differences in how libraries conduct outreach, including variance in monetary support for outreach programs and differences in staffing strategies. ${ }^{11}$ Some libraries provided dedicated outreach positions, while others relied on committees or teams. Most library mission statements did little to address outreach. They concluded, "[W]hile many libraries participate in different types of outreach, they often do so through informal and ad hoc ways without the benefit of systematic and well thought out outreach programs."12 The library literature would be well served by additional studies that research and demonstrate the value of systematic approaches to library outreach programs.

One approach to solving the lack of intentionality in outreach programs is already used effectively in library instruction programs: curriculum mapping. For several decades, librarians have reviewed course syllabi and mapped curricula to inform their instruction efforts. There are a number of articles detailing how libraries conducted syllabus studies and curriculum mapping to better understand faculty and student use of the library and to identify potential insertion points for course-integrated instruction. Rambler's foundational syllabus study presented a case for reviewing syllabi to better understand how library resources were being used in courses and to inform the design of library instruction programs, including recommendations that libraries explore systematic expansion of instruction in upper-division undergraduate courses. ${ }^{13}$ VanScoy and Oakleaf conducted a syllabus study to inform appropriate scaffolding of information literacy skills in a curriculum-integrated instruction model, concluding that there was a mismatch between the skills students were asked to perform in their first-year of college and the skills covered at the first-year level in many curriculum-integrated instruction programs. ${ }^{14}$ Other librarians conducted syllabus studies to identify potential new instruction opportunities ${ }^{15}$ or to identify missed opportunities for instruction collaboration and inform faculty outreach efforts. ${ }^{16}$

Although curriculum mapping is a methodology frequently used in school libraries, academic libraries have adopted this methodology not only to identify potential areas for library instruction, but as a tool that facilitates both curriculum analysis and communication with disciplinary faculty. Bullard and Holden noted that "A common theme among all uses and applications of curriculum mapping is improved communication and collaboration." ${ }^{17}$ Successful curriculum mapping projects actively involve stakeholders, including library colleagues, departmental faculty, and college or university administrators. ${ }^{18}$ After completing curriculum maps at each of their respective universities, Buchanan, Webb, Houk, and Tinglestad 
observed, "One key strength of the curriculum mapping process is that it clearly illustrates both problems and opportunities in regard to integrating information literacy skills into the curriculum." ${ }^{19}$ This communication frequently takes the form of presentations to faculty or reports to each department or college. ${ }^{20}$

Curriculum maps provide librarians with a visual overview of a department or college's curriculum and are created with a variety of information sources. Common data sources include: degree program requirements, departmental learning outcomes, course syllabi, individual course requirements, and enrollment data. ${ }^{21}$ Many librarians also examine internal library data to identify existing library instructional efforts. Such data sources include library instruction statistics, reference consultation statistics, and even LibGuides. ${ }^{22}$ Additionally, librarians map their programs and learning outcomes to existing frameworks outside their college or university curriculum such as the now-rescinded Association of College \& Research Libraries (ACRL) Standards or the ACRL Framework..$^{23}$

\section{Methodology}

The researchers initiated an action research methodology to investigate the utility of a curriculum mapping approach for a combined outreach/instruction map. Action research is an inquiry process for solving problems or creating change while also engaging in a research process. Kurt Lewin, often credited with the creation of the action research spiral, illustrated the steps of action research as a descending circle of planning, analyzing, and replanning to create desired outcomes. ${ }^{24}$ Kemmis, McTaggart, and Nixon revised the traditional spiral to accommodate the self-reflection inherent in the process. ${ }^{25}$ Although Kemmis, McTaggart, and Nixon admit that the process doesn't always follow a linear progression of steps, the distinctive phases are as follows: ${ }^{26}$

- Planning a change

- Acting and observing the process and consequences of the change

- Reflecting on these processes and consequences

- Replanning

- Acting and observing

- Reflecting and so on

The action research methodology is ideally suited for curriculum mapping for several reasons. The iterative nature of an action research methodology dovetails with the cyclical nature of the outreach and instruction cycle in the academic year. As each year closes, researchers can reflect, revise, and replan. An action research methodology is also flexible, allowing for the insertion of new outreach activities or instructional opportunities into the plan. In addition, educational environments, by nature, have frequent turnover in their student body and staff. Action research methodology calls for constant assessment and reassessment, which allows for changes in the makeup of the student and staff populations in a university setting. Finally, action research is self-reflective and participatory. The method requires critical reflection upon instruction practices to understand how and why desired outcomes are being achieved.

The researchers used an action research model to inform the curriculum mapping process. The project addressed the research questions and the need for change within the instruction and outreach programs to respond to institutional growth and changing institutional priorities. The subsequent sections follow the steps of the action research model. 


\section{Planning for Change}

The first phase in the action research method was planning for change. To focus the study and maintain a limited scope, the researchers decided to concentrate on library instruction and outreach for first-year students. This early phase of the curriculum mapping project was extensive, as it required developing learning outcomes for instruction and outreach, creating a framework to inform data collection, gathering existing data, and consulting calendars and institutional memory to fill gaps in existing data.

\section{Step 1: Developing Outcomes for Outreach and Instruction}

The first step was the development of outcomes for both outreach and instruction. It was also the lynchpin to the planning phase. Determining what students "will be able to do or know" when they complete an instruction session establishes the parameters of each class as well as the program curriculum. Outcomes also demonstrate intentionality, communicating that the library instruction program is planned and framed within a larger context of information literacy skills.

Fortunately, the first-year library instruction program had an established set of learning outcomes from which the curriculum mapping project could begin to take shape. The First Year Programs Coordinator had developed these outcomes as part of her work and aligned them with the ACRL Framework for Information Literacy for Higher Education. Examples include:

- Outcome 4.1: Students will be able to articulate their chosen topic in the form of appropriate search terms

- Outcome 4.2: Students will be able to find and select a source on their chosen topic

In addition to learning outcomes for instruction, the team of librarians responsible for many of the first-year student outreach activities had already developed goals. Those goals were used internally to recruit library staff to work at outreach events, assess outreach activities, and demonstrate the value of outreach to library administration. However, outreach planners had developed new goals for each outreach event, reflecting the lack of a strategic plan for how event-based outreach goals worked together toward a cohesive purpose. Upon review, the researchers also discovered that outreach goals tended to emphasize a different set of values from the instructional learning outcomes. Outreach goals tended to be affective in nature, emphasizing reduction in library anxiety or highlighting the library as a welcoming space. The goals lacked the operationalized criteria for success that is typical in instruction outcomes, such as attainment of certain skills. Outreach goals also placed a heavy emphasis on library resource awareness, as librarians try to educate new students about the suite of available library spaces and services. In contrast, learning outcomes focused on information literacy skill development, with a demonstrable skill that could be observed or measured.

To create a scaffolded curriculum map that included outreach, the researchers had to reconcile learning outcomes and outreach goals. The student learning outcomes developed for the first-year library instruction program and the library outreach goals were merged into a common structure. To differentiate them, two distinct sets of goals and outcomes were developed and standardized based on existing data and documentation. Instruction Goals refer to the broad programmatic goals that the first-year instruction program is trying to accomplish. Instruction Goals are complemented by Student Learning Outcomes (SLOs), narrower task-oriented skills that are demonstrable and measurable. Similarly, Outreach Goals are aspirations for a strategic outreach program. Three distinct outreach goals emerged: 1) 
Reduce Library Anxiety; 2) Promote Library Collection Awareness; and 3) Promote Library Service Awareness. Under each Outreach Goal, a list of Outreach Learning Outcomes (OLOs) were defined. Outcomes for outreach events can be difficult to define, assess, and attach to traditional measures of value in an academic setting. Therefore, these outcomes articulate the behaviors that are expected of students after participating in an outreach event. Examples include:

1. Outreach Goal 1: Reduce Library Anxiety

Outcome 1.1: Students will be able to identify the library as a friendly place

Outcome 1.2: Students will feel comfortable using the library or engaging with a librarian

\section{Step 2: Develop a Framezwork}

After developing SLOs and OLOs, the researchers took the next step of developing a framework for data collection. The project's research questions directly informed this framework. It included the specific data points the researchers planned to gather to answer research questions.

One of the most important questions was identifying which student populations were receiving library content through instruction and outreach and which student populations were not. In particular, the researchers were interested in reviewing student populations that were the subject of key campus initiatives. This included first-year students and students in underrepresented populations. Therefore, it was critical for the map to include data about the specific audiences served at each outreach and instruction activity.

In addition, the researchers chose to include data about population size. Some universitylevel programming aimed at underserved students is intentionally organized on a small scale to provide students with an opportunity to develop relationships and build a cohort identity. To get an accurate understanding of the Libraries' outreach and instructional reach, it was important not only to understand whether the library was providing instruction or outreach to specific populations, but also how many students were reached via these activities.

To understand how the Libraries' messaging was being crafted and delivered to each audience area, the researchers gathered data that would describe the number of times librarians saw a particular student population as well as the type and level of messaging delivered at each outreach or instruction opportunity.

\section{Step 3: Gathering Data}

Once a framework was developed, the next step was to begin gathering data. The researchers received institutional review board permission to use existing data from the University Libraries' instruction and outreach activities. The Director of Learning and Outreach is responsible for gathering instruction data from each of the five libraries and develops an instruction report on an annual basis. This existing instruction data included the course name and number, number of students, number of sessions, time of year, and duration of session but did not include learning outcomes or assessment techniques for each session. Additionally, the Learning and Outreach Program Assistant maintained an outreach event calendar that provided extensive outreach data for the map. The existing outreach data included the event name, time of year, audience, duration, and type of event (such as resource table or presentation) but did not include the number of participants, learning outcomes, or assessment techniques. Both the instruction and outreach data had limitations, as it is self-reported data from the librarians staffing those events and classes. However, the researchers had substantial first-hand knowl- 
edge of these activities and were able to identify data gaps and discrepancies that could be addressed using supplemental data.

To fill gaps in data, the researchers opted to consult alternate sources of outreach and instruction data. Lesson plans and alignment grids from the First Year Programs Coordinator proved invaluable. By consulting these records, the researchers were able to identify existing learning outcomes for specific library one-shots aimed at first-year students, including core curriculum writing intensive courses such as ENGL 104 and ENGL 203 and first-year learning community courses such as the Honors First Year Experience course. These records also included assessment strategies used for each session. Although analyzing these individual records was time-intensive, the labor involved was minimized due to the concentration of first-year instruction efforts under the domain of a single librarian.

The researchers also reviewed the event records for each outreach event. At the University Libraries, each major outreach event has a designated coordinator who plans, coordinates, and executes the outreach event. Reporting the event is a core function of the coordinator role, and each coordinator frequently maintains their own individual records about the planning of the event, the outreach learning outcomes, and the assessment conducted. Although anyone in the University Libraries may coordinate outreach events, the bulk of the outreach events for first-year students are coordinated by the First Year Programs Coordinator or other members of the Learning and Outreach department. This meant that, while the records for each event were somewhat dispersed, they were still available within the web ecosystem of the Learning and Outreach department or via a quick request to a colleague within the same department. Event records for each individual outreach event provided the researchers with data regarding the specific format of the outreach event, existing outcomes, and assessment strategies employed to measure the success of the event.

The Learning and Outreach department's promotional item, or swag, inventory database also provided data about outreach events for the map. Developed and maintained by the Learning and Outreach Program Assistant, the swag inventory database tracks the usage of library promotional materials. The University Libraries relies on the precise counting of promotional items before and after outreach events as a proxy for tracking attendance at events where counting attendance is impractical due to size or structure of the event. Through these data, the researchers gathered an estimate of attendance for each first-year outreach event.

\section{Acting and Observing}

The second phase of the action research model was acting on the plan for change and then observing the processes and consequences of that change. This was achieved in the development of the map. Given the data collected in the planning phase, the researchers opted to develop the map in a Google spreadsheet. They selected a spreadsheet application to accommodate the extensive number of events, columns, and rows necessary to encapsulate the scope of instruction and outreach in a single academic year. This platform also allowed for collaborative development in real time, easy viewing of any alterations, and sharing with other library staff and faculty. The appendix shows a snapshot of the map to provide a sample of how the project was approached. Due to the extensive size of the completed spreadsheet, the appendix displays only a limited sample of outreach events and instructional classes. 
The researchers designed the map to list instruction and outreach learning outcomes in the rows of the initial column, with all other data categories listed in heading columns along the top of the spreadsheet. They grouped the outcomes, developed during the planning phase of the project, into six major goals that represented the overall objectives of the first-year instruction and outreach program:

1. Outreach Goal 1: Reduce Library Anxiety

2. Outreach Goal 2: Promote Library Collection Awareness

3. Outreach Goal 3: Promote Library Service Awareness

4. Instruction Goal 4: Introduce Strategies for Finding Information

5. Instruction Goal 5: Introduce Evaluation and Selection of Information

6. Instruction Goal 6: Introduce Ethical Use of Information

The spreadsheet's horizontal rows included descriptive data that provided context to the map. These data were organized in columns according to time of year, with three major time groupings that correspond with the three semesters at the university. The time category was important as it indicated the order in which events occurred and therefore would inform the appropriate level at which learning outcomes should be scaffolded.

Beneath the time categories fell a number of other descriptive data points, including the event name, audience size, type of activity, and assessment strategy. The researchers chose each of these data points during the planning phase as part of the map framework and relevant to the project's research questions.

In addition to these descriptive data points, the researchers identified two critical pieces of information that would constitute the core of the map. The audience for the instruction/ outreach event was the first piece of information. The researchers identified six audience areas based on information regarding underserved and target populations at the university (see table 1).

The level of messaging or content was the second piece of information. One of the project research questions involves not only the learning outcomes for each event but also the scaf-

\begin{tabular}{|l|l|c|}
\hline \multicolumn{2}{|c|}{$\begin{array}{c}\text { TABLE 1 } \\
\text { Audience }\end{array}$} & Code \\
\hline Audience & Definition & F \\
\hline First-year students & $\begin{array}{l}\text { Students in their first year at the University for whom this } \\
\text { is their first time in college }\end{array}$ & G \\
\hline First-generation students & $\begin{array}{l}\text { Students who did not have a parent or guardian who } \\
\text { graduated from a four-year college }\end{array}$ & I \\
\hline International students & $\begin{array}{l}\text { Students who are not a citizen or permanent resident of } \\
\text { the United States }\end{array}$ & P \\
\hline Provisional-admission students & $\begin{array}{l}\text { Students conditionally admitted to the University via a } \\
\text { program such as Aggie Gateway to Success or TAMU- } \\
\text { Blinn TEAM }\end{array}$ & T \\
\hline Transfer students & $\begin{array}{l}\text { Students entering for the first time but who attended } \\
\text { another postsecondary institution }\end{array}$ & U \\
\hline $\begin{array}{l}\text { Underserved students (LGBTQ } \\
\text { students, students from traditionally } \\
\text { underrepresented groups, low- } \\
\text { income students) }\end{array}$ & $\begin{array}{l}\text { Students eligible for targeted programs or resource } \\
\text { centers on campus, including the GLBT Resource Center, } \\
\text { Multicultural Services, or Regents' Scholars }\end{array}$ & \\
\hline
\end{tabular}


folding and the level at which each learning objective is taught. Librarians can connect with students multiple times over the course of their orientation to campus, including resource tables and presentations at campus orientations and activities at the Libraries' annual Open House event. Some outreach learning outcomes remain constant across all three events (for example, Outcome 1.1:

\begin{tabular}{|l|c|}
\hline \multicolumn{2}{|c|}{$\begin{array}{c}\text { TABLE } \\
\text { Level }\end{array}$} \\
\hline Outreach/Instruction Level & Code \\
\hline Introduce & 1 \\
\hline Reinforce & 2 \\
\hline Enhance and Build & 3 \\
\hline
\end{tabular}

Students will be able to identify the library as a friendly place), but the level of messaging is differentiated to account for duration, event context, and previous delivery of messaging. Accordingly, the researchers identified the three levels below (see table 2).

A key at the bottom of the spreadsheet defined the audience and the level codes. Level 1 (Introduce) was defined as messages crafted to acquaint students with library services, collections, or information literacy concepts at a basic level. Level 2 (Reinforce) was defined as messaging that reminded students of introductory knowledge and provided supplementary information. Level 3 (Enhance and Build) was defined as messaging that helped students gain a more nuanced understanding of a concept. For example, librarians introduced students to the basic services offered by interlibrary loan at New Student Conferences. This was considered Level 1. Later, they reinforced that messaging (Level 2) at orientation camps and provided more information about document delivery to branch libraries. At the Open House event, librarians taught students how to apply for an interlibrary loan account and fill out a request (Level 3).

Once the researchers constructed the spreadsheet, they began populating the map. Consulting the data gathered during the planning stage, the researchers added to the map each major instruction or outreach activity aimed at or including substantial numbers of first-year students. Once each event was added, the researchers consulted instruction and outreach statistics, as well as their own experience as instruction and outreach librarians, to identify the specific audiences and instruction levels for each event.

\section{Reflecting}

Once the map was fully populated, the researchers analyzed the map for both overlaps and gaps. Identifying gaps was a critical step in identifying student populations or outcomes that needed additional library instruction and outreach efforts. However, overlaps in student populations and/or outcomes were also important. Researchers hoped to identify redundant programming that could indicate an area where library activities could be reduced or where learning outcomes could be adjusted to eliminate redundancies and focus resources on other priorities.

The researchers found several areas of importance. First, although the researchers anticipated that student learning outcomes were being introduced during outreach events, the map revealed that this was not the case. The researchers posit that this was because outreach activities were not structured to achieve student learning outcomes, as many of them occurred outside the library for short periods of time with very large groups of students. In addition, student learning outcomes often required context that was not available at an outreach event, which did not typically include assignments or other required tasks. Finally, student learning outcomes were structured so students could demonstrate skills or changes in behavior, which was difficult to accomplish during outreach events. 
Although student learning outcomes were not present during outreach events, the map confirmed that outreach learning outcomes were being addressed during instruction sessions. This frequently occurred at the request of course instructors who wanted to ensure that their students were familiar with library resources and services. The outreach learning outcomes addressed during instruction sessions were almost exclusively higher-level outcomes. This suggests that, while librarians were unable to leverage the large-scale format of outreach activities to achieve student learning outcomes, they were successful at achieving higher-level outreach learning outcomes within the smaller-scale context of an instruction session. While additional research is needed to determine why this occurred, the researchers posit that timing may have been a root cause. Instruction sessions were longer in duration, lasting an hour or more, while a librarian's engagement at outreach events may be limited to minutes or a half-hour at most.

The researchers also determined that more of their instruction and outreach efforts were focused on traditional first-year students than they had anticipated. The University Libraries had been increasing outreach efforts to specific underserved populations, including first-generation college students, Lesbian/Gay/Bisexual/Transgender/Queer (LGBTQ) students, veteran and military-affiliated students, and students from traditionally underrepresented groups. This included activities such as the Libraries' resource table at the campus' Rainbow Resource Fair. However, often these activities were aimed at any students who identified as members of these underserved populations, regardless of their year in school. Therefore, many of these activities were excluded from the first-year map, as they were not specifically aimed at firstyear students, and it is unclear how many of the attendees actually were first-year students. The process of creating the map revealed that while the Libraries participated in outreach efforts aimed at underserved populations, these efforts were not specifically oriented toward first-year members of these populations. This observation led the researchers to reflect on the structure of the Libraries' instruction and outreach efforts for specific underserved populations and consider whether they could shift some of the outreach focus from the traditional first-year student populations to underserved first-year students.

Researchers also observed unexpected findings about how outreach learning outcomes were scaffolded for first-year orientation activities. The researchers were aware that the campus's orientation program provided multiple opportunities to engage with students throughout the summer. Accordingly, the researchers had developed a programmatic approach to firstyear orientation outreach efforts, including development of a first-year orientation outreach campaign theme that carried through summer orientation outreach activities. However, when the researchers examined the learning outcomes for these orientation outreach activities, they found that there was not much differentiation. Students who attended New Student Conferences ( $\mathrm{n} \sim 1,430)$, Fish Camp, or freshman orientation camp, $(\mathrm{n} \sim 7,103)$, and Open House (n $\sim 3,998$ ), three major first-year orientation events, received similar messaging about the Libraries. Although these outreach learning outcomes regarding library anxiety and collection awareness were scaffolded at different levels, intended to reinforce and build upon previously introduced information and concepts, there was considerable redundancy in content.

The map also revealed that there were a number of smaller orientation outreach activities that shared outreach learning outcomes with the larger, general orientation outreach activities. The University Libraries' outreach activities for the Corps of Cadets' Freshman Orientation Week (FOW) and for the Focus Fair, a resource fair for students participating in a learning 
community for Regents' Scholarship recipients, shared outreach learning outcomes with the Libraries' Open House event. Targeted resource fairs for student veterans (Vet Camp) and international students (International Student Conferences) shared outreach learning outcomes with New Student Conferences. Some of these overlaps were intentional; for example, Focus Fair was scheduled at the same time as Open House, so having shared outcomes made sense for those two particular events. However, the researchers needed to examine the target populations and the outcomes for orientation activities scheduled later in the summer to determine whether shared outcomes were causing redundancy in messaging for attendees at those resource fairs.

Finally, it became clear that the audience types defined in the original map were not granular enough to enable reporting on key student populations. The map included an audience code for U: Underserved Students (LGBTQ students, students from traditionally underrepresented groups, low-income students). However, the researchers needed more detailed information about student populations to fully identify groups underserved by current instruction and outreach programming and to be able to report activities supporting university priorities. The researchers determined that many of these populations needed to be assigned their own code in subsequent maps.

\section{Replanning, Reacting, and Reflecting Again}

Action research is an iterative process that seeks to understand research questions while also engaging in change. After planning, acting, and reflecting on the curriculum map, the next phase was to replan and begin the cycle anew. There were two facets to the replanning process. First, there were the changes made to instruction and outreach programs based on the initial findings from the map. These changes began during the 2017-2018 academic year and continue to be implemented. Additionally, there are changes to the map, data collection, and the mapping process that are underway based on the lessons learned from the initial mapping project. Changes to the program and changes to the map inform each other in an interlocked cycle of research, critical reflection, and practice.

After review of the original map, the researchers implemented an initial round of changes to the first-year instruction and outreach programs. To reach more underserved students, the Libraries' Learning and Outreach unit added new opportunities to the current list of activities, specifically oriented to underserved student populations. For example, the researchers partnered with other library and campus stakeholders and were awarded a university grant to develop and implement an embedded section of ENGL 104 specifically for first-generation, provisionally admitted students. Additionally, the researchers partnered with the campus Veteran Resource and Support Center to develop new outreach efforts for student veterans and service members. The researchers, together with colleagues in the Learning and Outreach unit, also increased efforts to develop partnerships with other programs on campus that support underserved students, including campus resource centers and learning communities. To add additional programming, however, issues of staffing and resource allocation had to be addressed. The outreach and instruction levels included on the map were useful when making staffing decisions. The map showed numerous outreach activities listed as a Level 1 (Introduce). Additionally, there were several repetitive activities, such as New Student Conferences, where the same library resource table was offered more than 20 times throughout the summer months. To free up time for new programming, 
librarians began training library student workers to staff library resource tables at repetitive Level 1 events.

The original map also uncovered areas of redundancy, particularly activities where the librarians were delivering the same Level 1 message at multiple venues, even to the same audiences. While repetition can be beneficial for helping students remember key points, repeating the same message meant that the library wasn't taking the opportunity to reinforce and build new knowledge about library services. The researchers reviewed the first-year events, corresponding messaging and audiences, and made changes to scaffold outcomes at Levels 2 (Reinforce) and 3 (Enhance and Build) as students progressed through their first year. Additionally, the researchers began conversations with stakeholders regarding which events could be eliminated to add more impactful activities.

Researchers have also begun modifications to instruction and outreach programming to better achieve learning outcomes. For example, the map revealed that outreach learning outcomes associated with the goal of Library Service Awareness were both introduced and reinforced over the course of several outreach events. This finding was important as librarians frequently received requests from instructors for a general overview of library services during instruction sessions. The map revealed that library service awareness was effectively achieved during outreach and librarians could use this information to help preserve precious instruction time to focus on student learning outcomes. Accordingly, librarians began using this information in conversations with course instructors when designing lesson plans in response to requests for one-shot library instruction. Additional changes to the outreach and instruction program included ways to increase the number of instructional opportunities at a Level 3. The map showed far fewer activities at this level than expected, both in the instruction programs and the outreach activities. Researchers are currently reviewing these higher-level learning outcomes, especially within the context of existing outreach activities that have the benefit of scalability. Researchers hope to identify ways that some of these outcomes could be feasibly introduced in an outreach context.

Changes to the map, data collection, and the mapping processes are also underway. Of course, changing the map underscores the issue of how data are collected for outreach events and classes. A newly revised instruction statistics database system was developed to help clarify the collection of instruction and outreach data. Unveiled in the fall of 2017, this new system asks library instructors to record an audience "type" for each session. These data can be used to populate the new map codes for audiences. Additionally, the researchers are considering adding the ability to calculate the attendance for each event as a percentage of a particular audience type. For example, if librarians give an orientation presentation to 800 first-year students in the Corps of Cadets and there are 1,000 first-year students in the Corps, the Libraries are reaching 80 percent of that particular student population. Knowing the percentage of students who received library messaging provides a quick overview of the relative reach of various activities. These data help in strategic planning and the allocation of resources. They can also help librarians determine appropriate learning outcomes and levels at which to pitch messaging. However, there are some limitations to this approach. While some outreach events, such as the Corps orientation presentation, have very clear and distinct student populations, other events do not. It would be impossible to calculate the number of first-generation students who visited a library booth at a resource fair or the number of LGBTQ students that attended Open House. Additionally, this approach does not account for 
overlapping populations at different events. A Corps student could attend multiple events, or could even belong to multiple audience types (for example, a student could be a member of the Corps and also be a member of a traditionally underrepresented group). Even with these limitations, some estimated tracking of student populations would be helpful in both planning and reporting. Target population percentage will be added to the next map only for events where the population is clearly defined and the relative number of students can be gleaned from campus reports.

One additional data point will be added to the map in the coming year. Each event will have a Staffing Level code to indicate if a student worker, library staff member, or librarian was involved in staffing the activity. After a year of data collection, this new data point will help uncover additional information about the levels of staffing relative to outcome Levels 1,2 , and 3. Results will inform the continued strategic allocation of staff time, a precious commodity in a busy program, as well as the continued development of service models and opportunities for training and development.

\section{Conclusion}

The University Libraries' first-year instruction and outreach curriculum mapping project demonstrated that curriculum mapping can be an effective tool for gaining insight into the interrelated outcomes of library instruction and outreach programs. Creating the map was instructive for the researchers, as it prompted them to reflect on past and current practice. The creation process highlighted the need for program-level outcomes for both the instruction and outreach programs; it also called attention to the disparate ways statistics were stored that hindered easy data collection. The completed map provided a useful overview of the synergies and differences between the library outreach and instruction programs in the first year of student life on the Texas A\&M campus. The map uncovered areas where the library was successful at delivering consistent messaging by repeating the same message to different student populations at targeted events. The map also highlighted redundancies, or activities where the same students were hearing the same message or seeing librarians multiple times. Mapping the audiences at the individual event and class level illuminated student populations that were well served by current programing and student populations that needed additional targeted programming, such as first-generation students. Most important, the researchers used the project results to enact meaningful change to reach targeted audiences and improve the strategic allocation of library resources and staff time. By creating and mapping consistent outcomes for both instruction and outreach activities, the library will be better equipped to scaffold programming so each interaction with students builds upon a prior experience. Programming can then be geared at the appropriate level, audience, and outcome. Curriculum mapping proved a useful method for creating strategic and intentional instruction and outreach programs that complement rather than compete with each other. 


\begin{tabular}{|c|c|c|c|c|c|c|c|c|c|c|c|c|}
\hline \multicolumn{13}{|c|}{$\begin{array}{c}\text { APPENDIX A } \\
\text { Sample Instruction and Outreach Curriculum Map }\end{array}$} \\
\hline & Summer Events & & & & & & & & & Fall Semester & & \\
\hline & \begin{tabular}{|l} 
New Student \\
Conferencess
\end{tabular} & Gateway & Fish Camp & T-Camp & Fow & open House & Focus & 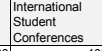 & vet Camp & ENGL 104 & ENGL 203 & ENGL 210 \\
\hline \begin{tabular}{|l} 
AUDIENCE Size \\
ACTIVITIES \\
\end{tabular} & resource table & tour & $\frac{711}{\text { presentation }}$ & presentation & 800 & 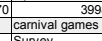 & $8 \underbrace{\frac{12 t}{4}}_{\text {resource table }}$ & $\frac{40}{\text { resource table }}$ & resource table & ${ }^{12}$ session & II session & \begin{tabular}{|l|l|l|}
5 session & 136 \\
\end{tabular} \\
\hline \begin{tabular}{|l|} 
ASSESSMENT Strategies \\
Outreach Gaol 1. Rexuce Library Anxiety
\end{tabular} & $\begin{array}{l}\text { Survey, } \\
\text { observation }\end{array}$ & Review artifacts & $\begin{array}{l}\text { Survey, } \\
\text { osservation }\end{array}$ & $\begin{array}{l}\text { Survey, } \\
\text { observation }\end{array}$ & $\begin{array}{l}\substack{\text { observation, } \\
\text { feedback }} \\
\end{array}$ & $\begin{array}{l}\text { Sunvery } \\
\text { counting } \\
\text { collection of } \\
\text { artificts, graftit } \\
\text { wall }\end{array}$ & $\begin{array}{l}\text { Observation, } \\
\text { feecback }\end{array}$ & $\begin{array}{l}\text { Observation, } \\
\text { feedback }\end{array}$ & $\begin{array}{l}\text { observation, } \\
\text { feedback } \\
\end{array}$ & Minute papers & Minute papers & Minute papers \\
\hline Outcome 1.1: Students will be able to identify the library as a friendly place & $\begin{array}{l}A: E, T \\
i: 1\end{array}$ & & $\begin{array}{ll}A: F \\
:: 2 \\
L: 2\end{array}$ & $\begin{array}{ll}A: T \\
\text { A:T } \\
L: 2\end{array}$ & \begin{tabular}{|l}
$A: F$ \\
$L: 3$ \\
$L$
\end{tabular} & $\begin{array}{ll}\text { A:ALL } \\
L: 3\end{array}$ & $\begin{array}{l}A: F, U \\
L: 1\end{array}$ & 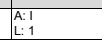 & $\begin{array}{l}A: F, T \\
L: 1\end{array}$ & & & \\
\hline $\begin{array}{l}\text { Outcome 1.2: Students will feel comfortable using the library or engaging with a } \\
\text { libraran }\end{array}$ & & $\begin{array}{l}\text { A:F, } P \\
L: 1\end{array}$ & & & & & & & & $\begin{array}{ll}A: F \\
L: 3 \\
L: 3\end{array}$ & 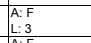 & $\begin{array}{ll}A: F \\
L: 3 \\
L: 3\end{array}$ \\
\hline Outcome 1.3: Students will become active library users & & & & & & & & & & $\begin{array}{l}A: F \\
L: 1 \\
L\end{array}$ & 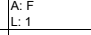 & $\begin{array}{l}\text { A: } \\
:: 1 \\
\text { F }\end{array}$ \\
\hline 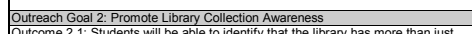 & & & & & & & & & & & & \\
\hline books 0 - & L:F:T, & 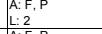 & $\begin{array}{l}\text { A:F } \\
:: 2 \\
L\end{array}$ & $\begin{array}{lll}A: T \\
:: 2\end{array}$ & $\begin{array}{lll}\text { A: }: 5 \\
: 3\end{array}$ & 存:AAL & 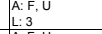 & 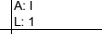 & 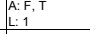 & & & \\
\hline 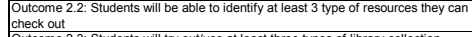 & & 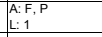 & & & & & 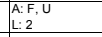 & & & 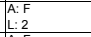 & 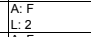 & 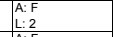 \\
\hline 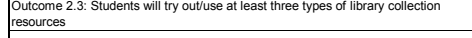 & & & & & & & & & & $\begin{array}{l}\text { A:F } \\
L: 1\end{array}$ & $\begin{array}{l}\text { A:F } \\
L: 2 \\
L: 2\end{array}$ & $\begin{array}{l}A: F \\
L: 2 \\
L\end{array}$ \\
\hline 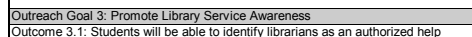 & $A: F, T$ & & & & & & & & & & & \\
\hline 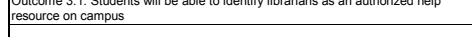 & L:F, & & & & & & & in: & 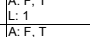 & 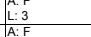 & 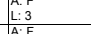 & 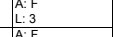 \\
\hline Outcome 3.2: Students will be able to identify a t least 3 types of library services & & $1: 2$ & Li: 1 & 管: 1 & ti: & 集: & & 焉: & 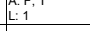 & 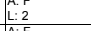 & ti: 2 & 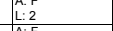 \\
\hline Outcome 3.3: Students will try outuse at least three types of fibrary services & & & & & & & & & & 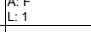 & 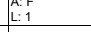 & 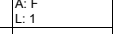 \\
\hline 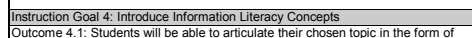 & & & & & & & & & & A. & & \\
\hline 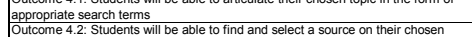 & & & & & & & & & & 泣: $1:$ & {$\left[\begin{array}{lll}2: 2 \\
A \cdot F\end{array}\right.$} & 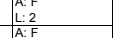 \\
\hline 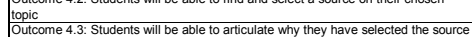 & & & & & & & & & & $\begin{array}{ll}\text { A } \\
\text { L: }: 1 \\
\text { A:F }\end{array}$ & 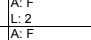 & 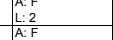 \\
\hline $\begin{array}{l}\text { they have chosen } \\
\text { Oulcome } 4.4 \text { S Sudents wil be able to identify citation information on a given }\end{array}$ & & & & & & & & & & L: $1:$ & $\begin{array}{ll}L: 2 \\
A: F\end{array}$ & $\begin{array}{l}\text { L:2 } \\
\text { A:F }\end{array}$ \\
\hline 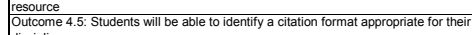 & & & & & & & & & & & & \\
\hline 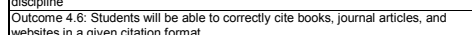 & & & & & & & & & & & & \\
\hline 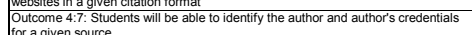 & & & & & & & & & & & & \\
\hline 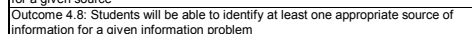 & & & & & & & & & & & 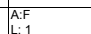 & $\left.\right|_{\substack{A \\
b=1}}$ \\
\hline 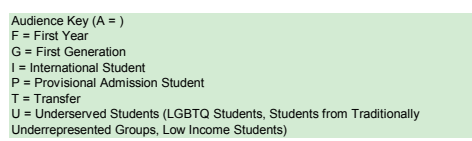 & & 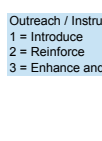 & $\begin{array}{l}\text { Iction Leve (L = } \\
\text { B Build }\end{array}$ & & & & & & & & & \\
\hline
\end{tabular}

\section{Notes}

1. Susan Gardner Archambault and Jennifer Masunaga, "Curriculum Mapping as a Strategic Planning Tool," Journal of Library Administration 55, no. 6 (2015): 503-19, doi:10.1080/01930826.2015.1054770; Heidi Buchanan, Katy Kavanagh Webb, Amy Harris Houk, and Catherine Tingelstad, "Curriculum Mapping in Academic Libraries," New Review of Academic Librarianship 21, no. 1 (2015): 94-111, doi:10.1080/13614533.2014.1001413; Kristen A. Bullard and Diana H. Holden, "Hitting a Moving Target: Curriculum Mapping, Information Literacy and Academe," in Moving Targets: Understanding our Changing Landscapes, eds. Theresa Valko and Brad Sietz (Ypsilanti, MI: Eastern Michigan, 2008), 17-21; A. Gabriela Castro Gessner and Erin Eldermire, "Laying the Groundwork for Information Literacy at a Research University," Performance Measurement and Metrics 16, no. 1 (2015): 4-17, doi:10.1108/ PMM-12-2014-0044.

2. Amy Van Scoy and Megan J. Oakleaf, "Evidence vs. Anecdote: Using Syllabi to Plan Curriculum-Integrated Information Literacy Instruction," College E Research Libraries 69, no. 6 (2008): 566-75, doi:10.5860/crl.69.6.566; Cheri Smith, Linda Doversberger, Sherri Jones, Parker Ladwig, Jennifer Parker, and Barbara Pietraszewski, “Using Course Syllabi to Uncover Opportunities for Curriculum-Integrated Instruction," Reference \& User Services Quarterly 51, no. 3 (2012): 263-71; Lisa M. Williams, Sue Ann Cody, and Jerry Parnell, "Prospecting for New Collaborations: Mining Syllabi for Library Service Opportunities," Journal of Academic Librarianship 30, no. 4 (2004): 270-75, doi:10.1016/j.acalib.2004.04.009.

3. Buchanan et al., "Curriculum Mapping in Academic Libraries”; Leslin H. Charles, "Using an Information Literacy Curriculum Map as a Means of Communication and Accountability for Stakeholders in Higher Education," Journal of Information Literacy 9, no. 1 (2015): 47-61, doi:10.7282/T3K939BT.

4. Melissa Dennis, “Outreach Initiatives in Academic Libraries, 2009-2011," Reference Services Review 40, no. 3 (2012): 368-83, doi:10.1108/00907321211254643.

5. Nancy Courtney, “Unaffiliated Users' Access to Academic Libraries: A Survey," Journal of Academic Librarianship 29, no. 1 (2003): 3-7.

6. Michele C. Russo and Nancy Wootton Colborn, "Something for (Almost) Nothing: Public Relations on a Shoestring in an Academic Library," Library Administration and Management 16, no. 3 (2002): 138-45; Wendi Arant and Charlene Clark, "Academic Library Public Relations: An Evangelical Approach," Library Administration and Management 13, no. 2 (1999): 90-95; Maureen Brunsdale, "From Mild to Wild: Strategies for Promoting Academic 
Libraries to Undergraduates," Reference \& User Services Quarterly 39, no. 4 (2000): 331-35.

7. Carole Ann Fabian, Charles D'aniello, Cynthia Tysick, and Michael Morin, "Multiple Models for Library Outreach Initiatives," Reference Librarian 39, no. 82 (2004): 39-55, doi:10.1300/J120v39n82_04.

8. Elizabeth Kennedy Hallmark, Laura Schwartz, and Loriene Roy, “Developing a Long-Range and Outreach Plan for Your Academic Library: The Need for a Marketing Outreach Plan," College E Research Libraries News 68, no. 2 (2007): 92-95.

9. Elizabeth Kennedy Hallmark, Laura Schwartz, and Loriene Roy, "The Basics of a Marketing and Outreach Plan for the UT Fine Arts Library," Texas Library Journal 83, no. 1 (2007): 40-43.

10. Dennis, “Outreach Initiatives in Academic Libraries, 2009-2011," 368-83.

11. Toni M. Carter and Priscilla Seaman, "The Management and Support of Outreach in Academic Libraries," Reference \& User Services Quarterly 51, no. 2 (2011): 163-71.

12. Ibid., 168.

13. Linda K. Rambler, "Syllabus Study: Key to a Responsive Academic Library," Journal of Academic Librarianship 8, no. 3 (1982): 155-59.

14. Van Scoy and Oakleaf, "Evidence vs. Anecdote," 566-75.

15. Cheri Smith et al., "Using Course Syllabi to Uncover Opportunities for Curriculum-Integrated Instruction," 263-71; Williams, Cody, and Parnell, "Prospecting for New Collaborations," 270-75.

16. Rick Bean and Lynn M. Klekowski, "Course Syllabi: Extracting Their Hidden Potential," in The Sixth Off-Campus Library Services Conference Proceedings (Mount Pleasant, MI: Central Michigan University, 1993), 1-9; Katherine Boss and Emily Drabinski, "Evidence-based Instruction Integration: A Syllabus Analysis Project," Reference Services Review 42, no. 2 (2014): 263-76, doi:10.1108/RSR-07-2013-0038.

17. Bullard and Holden, "Hitting a Moving Target," 17.

18. Buchanan et al., "Curriculum Mapping in Academic Libraries"; Charles, “Using an Information Literacy Curriculum Map," 47-61.

19. Buchanan et al., "Curriculum Mapping in Academic Libraries," 108.

20. Char Booth and Brian Mathews, "Understanding the Learner Experience: Threshold Concepts and Curriculum Mapping" (paper presented at California Academic \& Research Libraries Conference, San Diego, CA, 2012); Castro Gessner and Eldermire, "Laying the Groundwork for Information Literacy at a Research University," $4-17$.

21. Archambault and Masunaga, "Curriculum Mapping as a Strategic Planning Tool," 503-19; Buchanan et al., "Curriculum Mapping in Academic Libraries," New Review of Academic Librarianship 21, no. 1 (2015): 94-111, doi:10.1080/13614533.2014.1001413; Bullard and Holden, "Hitting a Moving Target," 17-21; Castro Gessner and Eldermire, "Laying the Groundwork for Information Literacy at a Research University," 4-17.

22. Buchanan et al., "Curriculum Mapping in Academic Libraries"; Bullard and Holden, "Hitting a Moving Target"; Castro Gessner and Eldermire, "Laying the Groundwork for Information Literacy at a Research University."

23. Buchanan et al., "Curriculum Mapping in Academic Libraries”; Susan Franzen and Colleen M. Bannon, "Merging Information Literacy and Evidence-Based Practice in an Undergraduate Health Sciences Curriculum Map," Communications in Information Literacy 10, no. 2 (2016): 245-63.

24. Kurt Lewin, "Action Research and Minority Problems," Journal of Social Issues 2, no. 4 (1946): 34-46.

25. Stephen Kemmis, Robin McTaggart, and Rhonda Nixon, The Action Research Planner: Doing Critical Participatory Action Research (Singapore: Springer Science \& Business Media, 2013).

26. Ibid., 18. 